\title{
Evaluation of Collagen Membranes Coated with Testosterone and Alendronate to Improve Guided Bone Regeneration in Mandibular Bone Defects in Minipigs
}

\author{
Bart A. J. A. van Oirschot ${ }^{1}$, John A. Jansen ${ }^{1}$, Cindy J. J. M. van de Ven ${ }^{1,2}$, Edwin J. W. Geven ${ }^{1,2}$, \\ Jan A. Gossen ${ }^{1,2}$ \\ ${ }^{1}$ Department of Dentistry - Biomaterials, Radboudumc, Radboud University Nijmegen, Nijmegen, The Netherlands. \\ ${ }^{2}$ Osteo-Pharma BV, Oss, The Netherlands.
}

\author{
Corresponding Author: \\ Bart A. J. A van Oirschot \\ Department of Dentistry - Biomaterials \\ Radboud University Nijmegen \\ Dentistry 309, Radboudumc, Ph v Leijdenln 25 \\ 6525 EX NIJMEGEN \\ The Netherlands \\ Phone: +31 243614027 \\ E-mail: bart.vanoirschot@radboudumc.nl
}

\begin{abstract}
Objectives: The purpose of the present in vivo study was to evaluate whether pericard collagen membranes coated with ancillary amounts of testosterone and alendronate in a poly-lactic glycolic acid (PLGA) carrier as compared to uncoated membranes will improve early bone regeneration.

Material and Methods: In each of 16 minipigs, four standardized mandibular intraosseous defects were made bilaterally. The defects were filled with Bio-Oss ${ }^{\circledR}$ granules and covered with a non-coated or coated membrane. Membranes were spraycoated with 4 layers of PLGA containing testosterone and alendronate resulting in 20,50 or $125 \mu \mathrm{g} / \mathrm{cm}^{2}$ of testosterone and $20 \mu \mathrm{g} / \mathrm{cm}^{2}$ alendronate (F20, F50, F125). Non-coated membranes served as controls (F0). Animals were sacrificed at 6 and 12 weeks after treatment. Qualitative and quantitative histological evaluations of bone regeneration were performed. Differences between groups were assessed by paired Student's t-test.

Results: Light microscopical analysis showed new bone formation that was in close contact with the Bio-Oss ${ }^{\circledR}$ surface without an intervening non-mineralized tissue layer. Histomorphometric analysis of newly formed bone showed a significant $20 \%$ increase in area in the F125 coated membrane treated defects (40 [SD 10]\%) compared to the F0 treated defects after 6 weeks (33 [SD 10] $\%, \mathrm{P}=0.013$ ). At week 12, the total percentage of new bone was increased compared to week 6 , but no increase in newly formed bone compared to F0 was observed.

Conclusions: The data from this in vivo study indicate that F125 collagen membranes coated with testosterone and alendronate resulted in superior bone formation $(+24 \%)$ when normalized to control sites using uncoated membranes.
\end{abstract}

Keywords: bone regeneration; bone substitutes; mandible; surgery; membranes; minipig.

Accepted for publication: 27 September 2020

To cite this article:

van Oirschot BA, Jansen JA, van de Ven CJ, Geven EJW, Gossen JA.

Evaluation of Collagen Membranes Coated with Testosterone and Alendronate to Improve Guided Bone Regeneration in Mandibular Bone Defects in Minipigs

J Oral Maxillofac Res 2020;11(3):e4

URL: http://www.ejomr.org/JOMR/archives/2020/3/e4/v11n3e4.pdf

doi: $\underline{10.5037 / j o m r .2020 .11304}$ 


\section{INTRODUCTION}

After tooth extraction, dimensions of the alveolar ridge and extraction socket significantly change because of a naturally occurring bone remodelling process [1]. A 50\% reduction in alveolar ridge width and height has been reported to occur within one year after tooth extraction [2]. Ridge dimensions are critical in implant therapy, as a reduced alveolar ridge poses a major limitation in the installation of dental implants [3]. As a consequence, bone regeneration procedures have been introduced to increase the ridge width and height to facilitate dental implant placement. The majority of guided bone regeneration (GBR) procedures involve the use of bone grafts and barrier membranes, which entails the installation of a bone graft particulate into the bone defect and coverage of the outside with a membrane to prevent ingrowth of soft tissues. The efficacy of this procedure has already been proven in multiple clinical studies, in which a wide variety of graft materials as well as membranes has been applied [4-7]. In GBR, the function of the bone graft material is to act as a scaffold for bone ingrowth. The primary function of the membrane is to act as a barrier that prevents soft tissue ingrowth between the graft granules.

Despite the reported favourable effect, there are also a lot of studies that are critical about the outcome and clinical predictability of these GBR and augmentation procedures $[\underline{8}, \underline{9}]$. It is recommended that further studies are done to optimize the osteogenic properties of the materials as used in these procedures [10]. In view of this, experiments have already been done using biomolecules (e.g. bone morphogenetic protein 2 [BMP2]) or mesenchymal stem cells to support alveolar bone regeneration. However, the final clinical effectiveness of these therapies is not evident and there is concern about the complexity, safety and costs of the involved processes [11-13]. Therefore, there is need to alternative simple and less costly materials, which still improve significantly the outcome of bone regeneration procedures.

Given the above mentioned, an experimental strategy to favour early bone formation in bone regeneration procedures involves the use of anti-osteoporotic drugs [14]. Such drugs are used to treat abnormal bone metabolism, like in osteoporosis. The drugs interfere in the bone turnover process by reducing bone breakdown and by stimulating bone deposition $[\underline{15}, \underline{16}]$. The most frequently used drugs belong to the class of bisphosphonates, e.g. alendronate and zoledronic acid, which are highly potent in the inactivation of osteoclast activity.
The anti-osteoporotic agents can be given alone as single drug therapy or as combination therapy in which different osteoanabolic agents (e.g. teriparatide, abolaparatide and romosozumab) are combined to achieve a supplementary effect on increase of the bone mass $[16,17]$. In fact, the combination of using both an anabolic and catabolic compound to improve local bone formation has previously been shown to result in synergistic effects on fracture healing [18]. Another important osteoanabolic agent is testosterone, as it directly stimulates the proliferation and differentiation of osteoblast cells $[19,20]$. In a critical-sized femoral segmental defect the local delivery of testosterone was effective in stimulating bone healing [21]. Recently, it was suggested to apply a similar combination therapy approach for bone regeneration using testosterone and alendronate [22]. The concept is based on the application of a poly-lactic glycolic acid (PLGA) solution containing testosterone and alendronate in ancillary amounts to activate osteoblasts and inhibit osteoclasts, respectively. Due to the observed synergistic effect of using alendronate in combination with testosterone significant effects on bone formation and bone mineral density (BMD) have been described [22]. The hypothesized advantage of using PLGA as a carrier is that a controlled and sustained release of testosterone and alendronate will be obtained. Controlled release of alendronate however, is not considered important due to the inherent characteristic of alendronate, unlike testosterone, to immediately bind to hydroxyapatite present in bone tissue. Studies using local application of bisphosphonates for bone healing have shown detrimental effects when using high concentrations. For this reason, alendronate was added in a fixed, optimal amount of $20 \mu \mathrm{g} / \mathrm{cm}^{2}$.

To study the synergistic effects of testosterone and alendronate in vitro bone explant studies were performed. Bone explants contain both osteoblasts and osteoclasts and hence can be used to simultaneously study the effects of anabolic and catabolic compounds independently and in combination. Moreover, as bone explants can be cultured up to 4 weeks bone biomarkers secreted into the culture medium can be measured over time and the bone explants can be analysed by $\mu \mathrm{CT}$ to determine the effects on various bone parameters such BMD and bone volume [23] .

Consequently, the aim of the present study was to evaluate whether guided bone regeneration using collagen membranes coated with ancillary amounts of testosterone and alendronate in a poly-lactic glycolic acid carrier as compared to uncoated membranes will improve early bone formation. Therefore, an in vitro study with bone biopsies as well as an in vivo study in minipigs was performed. 


\section{MATERIAL AND METHODS \\ In vitro study on bone explants Porcine bone specimens}

Bone biopsies were taken from fresh porcine knees obtained at a local abattoir. Three cylindrical bone biopsies (7 $\mathrm{mm}$ diameter) per condyle were taken from the femur with a trephine drill. The biopsies were washed two times with phosphate buffered saline (PBS) before they were cultured in alphaminimum essential medium ( $\alpha$-MEM) (Invitrogen Corp.; Carlsbad, CA, USA) supplemented with 100 $\mathrm{U} / \mathrm{ml}$ penicillin, $100 \mu \mathrm{g} / \mathrm{ml}$ streptomycin (Invitrogen) and $10 \%$ fetal bovine serum (Hyclone $^{\mathrm{TM}}$ - GE Healthcare; Chicago, IL, USA), $50 \mu \mathrm{g} / \mathrm{ml}$ ascorbic acid (Sigma-Aldrich Co.; St. Louis, MO, USA), 10 $\mathrm{nM} \beta$-glycerolphosphate (Sigma-Aldrich) and $75 \mathrm{nM}$ dihydrotestosterone (Tokyo Chemical Industry Co.; Tokyo, Japan), $2 \mu \mathrm{M}$ alendronate (Tokyo Chemical Industry Co.) or a combination of both. Biopsies were cultured under standard culturing conditions $\left(37^{\circ} \mathrm{C}\right.$, $5 \% \mathrm{CO}_{2}$ and $95 \%$ humidity) and medium (including dihydrotestosterone and alendronate) was replaced twice per week. Following 7 days of culturing, the alkaline phosphatase (ALP) activity in the culture medium was determined with a luminescence assay (CDP-Star ${ }^{\mathbb{B}}$, ready-to-use - F. Hoffmann-La Roche Ltd; Basel, Switzerland). After 4 weeks, biopsies were scanned with $\mu \mathrm{CT}$ (Skyscan 1076 system Bruker-MicroCT; Kontich, Belgium) with a voxel size of $9 \mu \mathrm{M}$, an energy of $59 \mathrm{kVp}$; a current of 200 $\mu \mathrm{A}$; and an integration time of $2200 \mathrm{~ms}$. The scans were reconstructed with NRecon software (BrukermicroCT) and analysed with CTan software (BrukermicroCT) to assess bone volume fraction (BV/TV), bone surface density (BS/TV), trabecular thickness (Tb.Th), trabecular separation (Tb.Sp) and trabecular number (Tb.N) in the trabecular bone. Following $\mu \mathrm{CT}$, bone strength of the biopsies was measured using a compression test (H10KT - Hounsfield Test Equipment Ltd.; Redhill, UK). The compression assay was performed by using a pre-load of $1 \mathrm{~N}$ and a cross-head speed of $1 \mathrm{~mm} / \mathrm{s}$. The compression loaddisplacement curves obtained during this test were further used to calculate the compression strength $\left(\sigma_{\varrho}\right)$.

\section{Human bone specimens}

Human bone biopsies were taken from femur material obtained from osteoarthritic (OA) patients that underwent knee replacement surgery at the Radboud University Medical Center ( $\mathrm{n}=13$ patients). Multiple cylindrical bone biopsies (7 $\mathrm{mm}$ in diameter) were taken with a hollow pipe and biopsies were washed two times with PBS before they were cultured in $\alpha$-MEM (Invitrogen) supplemented with $100 \mathrm{U} /$ $\mathrm{ml}$ penicillin, $100 \mu \mathrm{g} / \mathrm{ml}$ streptomycin (Invitrogen), amphotericine $2.5 \mu \mathrm{g} / \mathrm{ml}$ (Sigma-Aldrich) and 10\% fetal bovine serum (Hyclone ${ }^{\mathrm{TM}}$ ), $50 \mu \mathrm{g} / \mathrm{ml}$ ascorbic acid (Sigma-Aldrich) and $10 \mathrm{nM} \beta$-glycerolphosphate (Sigma-Aldrich). From each donor 3 - 10 biopsies (65 biopsies in total) were used as control and $3-8$ biopsies were treated with $75 \mathrm{nM}$ dihydrotestosterone (Tokyo Chemical Industry) and $2 \mu \mathrm{M}$ alendronate (Tokyo Chemical Industry), which was added to the culture medium. Biopsies were cultured under standard conditions $\left(37{ }^{\circ} \mathrm{C}, 5 \% \mathrm{CO}_{2}\right.$ and $95 \%$ humidity) and medium (including dihydrotestosterone and alendronate) was replaced twice per week. After 4 weeks, biopsies were scanned with $\mu \mathrm{CT}$ (Skyscan 1076 system - Bruker-MicroCT) with a voxel size of $9 \mu \mathrm{M}$, an energy of $59 \mathrm{kVp}$; a current of $200 \mu \mathrm{A}$; and an integration time of $2200 \mathrm{~ms}$. The scans were reconstructed with NRecon and analysed with CTan software (Bruker-MicroCT) to assess BV/TV, BS/TV, Tb.Th, Tb.Sp, Tb.N and BMD in the trabecular bone and the average of the control and treated group of each donor was calculated.

\section{In vivo minipig study \\ Preparation and characterization of pericardium membranes}

Non-sterilized Good Manufacturing Produced porcine pericardium membranes $(4 \quad \mathrm{x} \quad 3 \mathrm{~cm}$ ) (European Medical Contract Manufacturing; Nijmegen, The Netherlands) were coated on the rough side using a Prism 500 ultrasonic spray coater (Ultrasonic Systems Inc.; Haverhill, MA, USA). Membranes were coated with 4 layers of acetonitrile containing 5\% PLGA (PURASORB PDLG 5004A - Corbion Group Netherlands B.V.; Amsterdam, The Netherlands), testosterone and micronized alendronate resulting in 20,50 or $125 \mu \mathrm{g} / \mathrm{cm}^{2}$ of testosterone (Aspen Pharmacare; Durban, South Africa) and $20 \mu \mathrm{g} /$ $\mathrm{cm}^{2}$ alendronate (Polpharma; Starogard Gdański, Poland) and coated membranes were dried overnight in a vacuum oven at room temperature. The next day, the membranes were coated 4 times with $5 \%$ PLGA (PURASORB PDLG 5004A - Corbion Group Netherlands B.V.) without testosterone and alendronate and dried over 3 days in a vacuum oven at room temperature. Coated as well as non-coated membranes (controls) were then cut into appropriate size $(2 \times 1 \mathrm{~cm})$ and packed into double Tyvek pouches and marked F0, F20, F50 and F125, respectively. Final sterilization was performed by gamma irradiation with 25 kGy (Synergy Health Ede B.V.; Ede, The Netherlands). 
To determine the in vitro release of testosterone, F20, F50 and F125 membranes $(\mathrm{n}=3)$ were placed in $2.5 \mathrm{ml}$ PBS containing $0.5 \%$ sodium dodecyl sulphate at $37{ }^{\circ} \mathrm{C}$ and at day $1,7,14,21,28,35$ and 49 a sample was taken. For determination of total content of testosterone, membranes $(n=3)$ were placed in acetonitrile for $60 \mathrm{~min}$ to dissolve the PLGA coating and the testosterone within. Testosterone concentration in PBS (in vitro release) and acetonitrile (total content) was determined with high performance liquid chromatography (Agilent 6125 - Agilent Technologies; Baden-Württemberg, Germany) on a ZORBAX Eclipse Plus C18 column (Agilent Technologies). In vitro release of alendronate was not determined as alendronate was added as a fixed amount of $20 \mu \mathrm{g} / \mathrm{cm}^{2}$ which was validated in previous experiments (data not shown).

\section{Minipig surgical procedures}

Sixteen adult Göttingen minipigs were obtained from Ellegaard (Dalmose, Denmark) and used as experimental animals. All surgical procedures were performed at the Radboudumc Animal Research facility (Nijmegen, The Netherlands) after the Dutch Central Committee on Animal Research and the local Ethical Committee on Animal Research of the Radboud University approved the study under project license AVD1030020185825 and protocol 2018-0004, respectively.

Before surgery all animals were given an intramuscular injection of $10 \mathrm{mg} / \mathrm{kg}$ ketamine (Alfasan Co.; Woerden, The Netherlands), midazolam $\left(0.6 \mathrm{mg} / \mathrm{kg}\right.$ body weight) (Dormicum ${ }^{\circledR}$ injection - Roche Laboratories; Almere, the Netherlands) and atropine $(50 \mu \mathrm{g} / \mathrm{kg}$ body weight) (Centrafarm Pharmaceuticals B.V.; Etten-Leur, The Netherlands). Also, prophylactic amoxicillin $(50 \mu \mathrm{g} / \mathrm{kg}$ body weight) (Centrafarm Pharmaceuticals B.V) was administered by intravenous (i.v.) infusion.
General anaesthesia was induced by propofol i.v. $\quad(2.5 \mathrm{mg} / \mathrm{kg}$ body weight) (Fresenius Kabi; Hertogenbosch, The Netherlands) and was maintained after tracheal intubation with Isoflurane $(1.0-1.5 \%)$ (Isoflutek - Laboratorios Karizoo; Barcelona, Spain). After shaving and cleaning the surgical sites with chlorhexidine (5 $\mathrm{mg} / \mathrm{ml}$ in $70 \%$ ethanol), a combination of lidocaine $(10 \mathrm{mg} / \mathrm{ml})$ (FreseniusKabi) and bupivacaine (5 $\mathrm{mg} / \mathrm{ml}$ ) (Aurobindo Pharma B.V.; Zwijndrecht, The Netherlands) was administered at the surgical sites for intraoperative analgesia. Then, an extraoral sub-angular incision was made bilaterally, exposing the lateral portion of the mandibular body and ramus of the minipig. Four standardized intraosseous defects measuring $8 \mathrm{~mm}$ in diameter and $4 \mathrm{~mm}$ in depth were made in the anterior region of the mandible distal from the first premolar (two at the right and two at the left side of the jaw). During drilling, sterile saline was used to prevent heating of the drill and to protect the surrounding bony structures (Figure 1A). The defects were filled with Small Geistlich Bio-Oss ${ }^{\circledR}$ granules $(0.25-1$ $\mathrm{mm}$ ) (Geistlich Pharma AG; Wolhusen, Switzerland) (Figure 1B) and covered with a non-coated or coated membrane (all four dosages were applied per animal), ensuring that dosages were equally distributed between bone defect locations. All membranes were fixed at the corners with titanium pins (Straumann AG; Basal, Switzerland) (Figure 1C). The soft tissues were closed in multiple layers by using resorbable sutures (Vicryl ${ }^{\circledR}$ 3-0 and 2-0 - Ethicon; Norderstedt, Germany). Immediate postoperative pain was controlled by a buprenorphine patch $(20 \mu \mathrm{g}$ /hour $)$ $\left(\right.$ BuTrans $^{\circledR}$ - Mundipharma Pharmaceuticals B.V.; Mechelen, Belgium) and meloxycam (5 mg/ml) (Novem - Boehringer Ingelheim; Ingelheim am Rhein, Germany) was given per 24 hours after surgery. The animals were checked daily for any possible infections.

Animals were divided into 2 groups $(\mathrm{n}=8)$

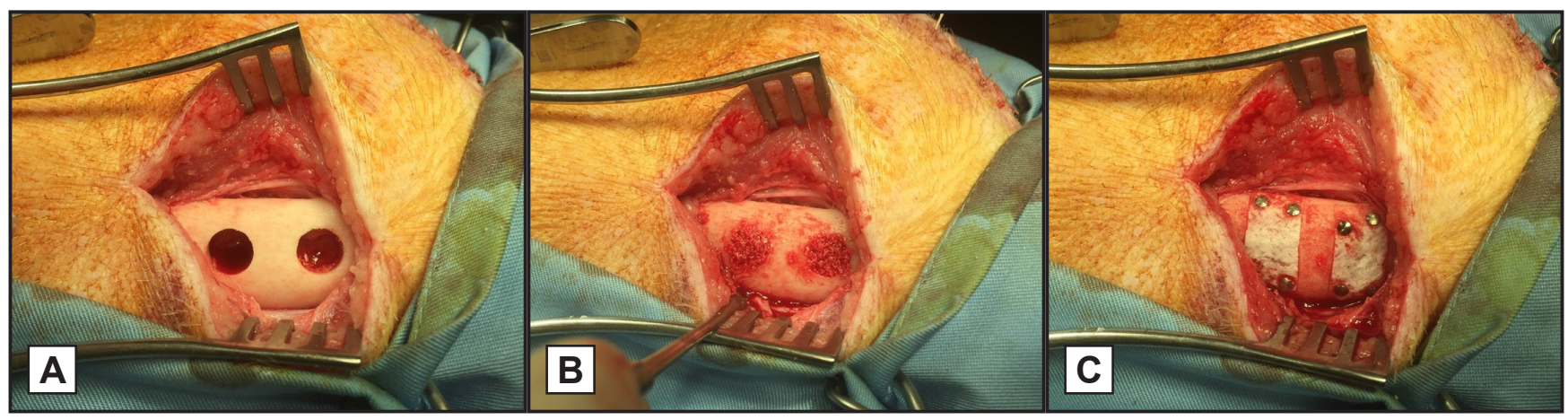

Figure 1. Minipig surgical procedures. $A=$ Two $8 \mathrm{~mm}$ diameter cylindrical defects were created in the left and right side of the mandible; $\mathrm{B}=$ the defects were filled with Bio-Oss ${ }^{\circledR}$ granules soaked in blood; $\mathrm{C}=$ covered with a collagen membrane which was fixed to the mandible by titanium pins. 
and defects were allowed to heal for 6 and 12 weeks. At the end of each designated healing period, animals were euthanized. The mandibles were harvested, excess soft tissue was removed and with a circular saw the apical side was trimmed to remove teeth and the mandible was further trimmed to approximately $4 \mathrm{~cm}$ in length. After removal of the marrow the mandibles were placed in $4 \%$ formaldehyde.

\section{Micro computed tomography analysis}

After fixation in 4\% formaldehyde for 14 days, the specimens were placed in $70 \%$ ethanol and $\mu \mathrm{CT}$ measurements were performed on a $\mu \mathrm{CT} 100$ imaging system (Scanco Medical; Brüttisellen, Switzerland). The parameters used for scanning involved an isotropic voxel size of $11.4 \mu \mathrm{m}$; an energy of 70 $\mathrm{kVp}$; a current of $200 \mu \mathrm{A}$; and an integration time of $320 \mathrm{~ms}$. Based on the comparison of $\mu \mathrm{CT}$ images to corresponding histological sections, thresholds were defined to segment new bone and Bio-Oss ${ }^{\circledR}$ granules from the images. On a range of $0-1000$, the threshold for new bone was set to $310-499$ and for Bio-Oss ${ }^{\circledR}$ a threshold of $500-1000$ was used. For the selection of new bone, a rod shaped region of interest (ROI) (2 $\mathrm{mm}$ in diameter and $6 \mathrm{~mm}$ long) was set, located in the top region of the defect and $1 \mathrm{~mm}$ from the defect border, then BV/TV and BMD was assessed in the ROI using $\mu \mathrm{CT}$ Analysis Software (Scanco Medical).

\section{Histological preparation}

After performing $\mu \mathrm{CT}$ scanning, the specimens were dehydrated in a graded series of ethanol
(70 - 100\%), after which they were embedded in polymethylmethacrylate (pMMA). After polymerization, thin sections of $15-20 \mu \mathrm{m}$ were prepared in a transverse plane perpendicular on the longitudinal direction of the mandible using a diamond blade microtome (Leica SP 1600 - Leica Microsystems; Nussloch, Germany). The first section of each specimen was aimed at the center of the defect or slightly more on the mesial side of the jaw and continued distally. Then, sections of each specimen were stained with methylene blue and basic fuchsine. At least, three sections of the center area of the defect were used for histological histomorphometrical analysis.

\section{Descriptive histology and histomorphometrical analysis}

The pMMA sections of the center area of the defect for each implantation time were examined by light microscopy (Leica Microsystems AG; Wetzlar, Germany). Quantitative assessment of the pMMA specimens was performed using computer-based image analysis software - Image $\mathrm{J}^{\circledR}$ version 2.0.0-rc43/1.52n (Fiji distribution; National Institute of Health, Bethesda, Meryland, USA). From digitalized images of the sections a ROI of $6 \times 2 \mathrm{~mm}$ was positioned in the center and top-region of the defect leaving $1 \mathrm{~mm}$ free of the defect border (Figure 2). When the diameter of the defect in the sections had a different size, the ROI was adapted accordingly. Within the ROI the contours of newly formed bone, Bio-Oss ${ }^{\circledR}$ and non- mineralized tissue were drawn manually (Wacom Cintiq 16 - Wacom Co., Ltd.; Kazo, Japan).

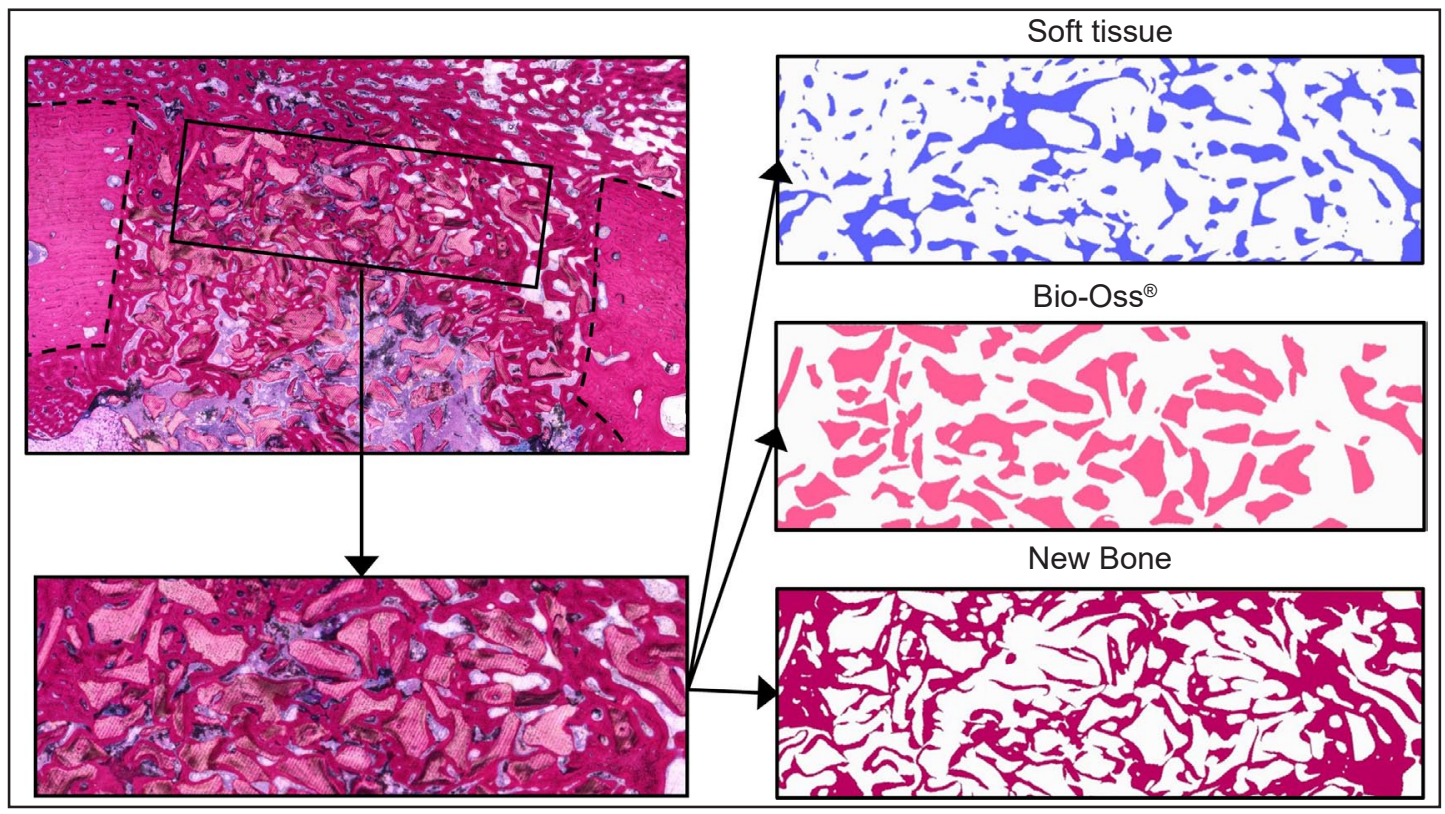

Figure 2. Illustration of the histomorphometrical procedure. 
After drawing, the contours were filled, and the images were converted to binary images. With the measurement function of Image $^{\circledR}$, total area of newly formed bone and Bio-Oss ${ }^{\circledR}$ were subsequently measured.

\section{Statistical analysis}

All data are expressed as mean and standard deviation (M [SD]). The size of the experimental groups (n) is given in parentheses. Differences between groups were assessed by paired Student's t-test. Statistical significance was set at $\mathrm{P}<0.05$ (two-tailed) and probabilities are indicated by asterisks $(* \mathrm{P}<0.05$, $* * \mathrm{P}<0.01$ and $* * * \mathrm{P}<0.001)$.

\section{RESULTS}

In vitro studies

Porcine bone specimens

After 7 days of culturing ALP activity in porcine biopsies stimulated with a combination of dihydrotestosterone and alendronate was significantly increased $(218[31] \%, \quad \mathrm{P}=0.007$, unpaired Student's t-test), while biopsies stimulated with dihydrotestosterone or alendronate alone did not (Figure 3A). After 28 days of culturing, BV/TV, BS/ $\mathrm{TV}, \mathrm{Tb} . \mathrm{Th}$ and $\mathrm{Tb} . \mathrm{N}$ were significantly increased (140 $[10] \%, \mathrm{P}=0.007,120[4] \%, \mathrm{P}=0.015,120[10] \%$, $\mathrm{P}=0.043,118[4] \%, \mathrm{P}=0.042$, respectively,

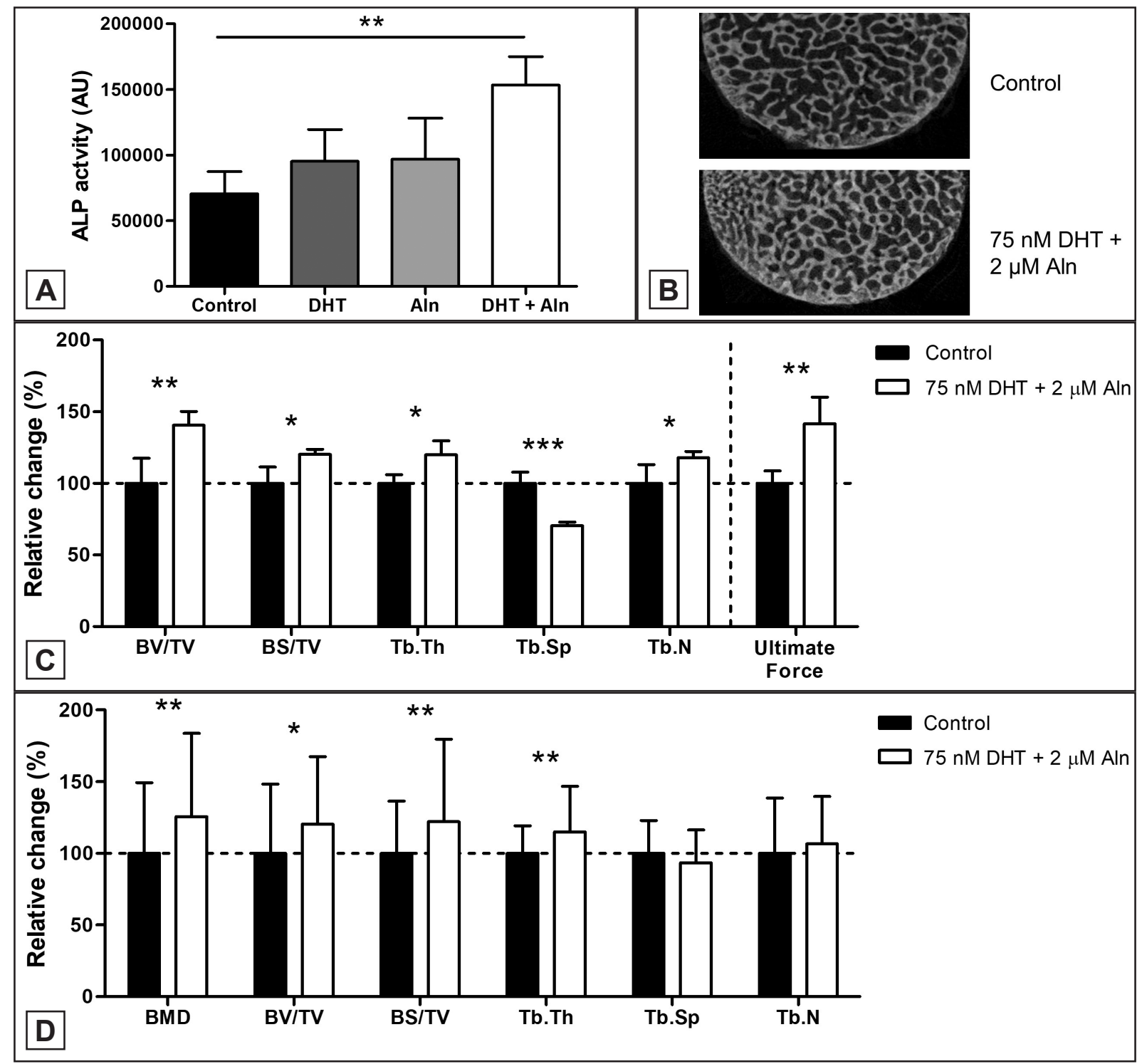

Figure 3. Porcine and human femur bone explant stimulated with dihydrotestosterone (DHT) and alendronate (Aln).

$\mathrm{A}=$ ALP activity in culture medium of porcine femur bone explants $(\mathrm{n}=3)$ stimulated for 7 days with DHT, Aln or a combination of both. $\mathrm{B}$ and $\mathrm{C}=2 \mathrm{D} \mu \mathrm{CT}$ reconstruction and $(\mathrm{C}) \mu \mathrm{CT}$ analysis of trabecular bone parameters and bone strength of porcine bone explants $(\mathrm{n}=3)$ stimulated with DHT and Aln after 28 days compared to a non-stimulated controls;

$\mathrm{D}=$ analysis of trabecular bone parameters of human osteoarthritic femur bone explants stimulated with DHT $(\mathrm{n}=65)$ and Aln $(\mathrm{n}=62)$ compared to non-stimulated controls. 
unpaired Student's t-test) when the biopsies were stimulated with a combination of dihydrotestosterone and alendronate, while Tb.Sp was significantly decreased $(70[3] \%, P=0.0003$, unpaired Student's t-test) (Figure 3B, C). Additionally, a significant increase in bone strength was observed in biopsies stimulated with both dihydrotestosterone and alendronate (141 [19]\%, P = 0.007, unpaired Student's t-test) (Figure 3C).

\section{Human bone specimens}

Stimulation of human bone from OA patients with a combination of dihydrotestosterone and alendronate for 28 days resulted in a significant increase in BMD (126 [58]\%, P = 0.0084), BV/TV (120 [47]\%, P = $0.016), \mathrm{BS} / \mathrm{TV}(122[58] \%, \mathrm{P}=0.009$, Tb.Th $(115$ $[32] \%, \mathrm{P}=0.001)$, while Tb.Sp and Tb.N remained unchanged (Figure 3D).

\section{In vivo study \\ Release characteristics}

Analysis of the in vitro release of testosterone from the coated membranes revealed that there was no burst release of testosterone, as the percentage released is $23(7) \%, 19(1) \%$ and $34(6) \%$ after 24 hours, for F20, F50 and F125 membranes respectively (Figure 4). Release of testosterone continued over a period of 3 - 4 weeks. Analysis of total content of testosterone showed that the F20, F50 and F125 membranes contained 43, 128 and $241 \mu \mathrm{g}$ of testosterone, respectively, which is 7,28 and $4 \%$ from the aimed amount of testosterone (40, 100 and $250 \mu \mathrm{g}$, respectively).

\section{Clinical findings}

Healing was uneventful and no signs of inflammation could be observed at the surgical sites. The minipigs remained in healthy conditions during the study.

\section{Micro computed tomography}

Thresholding of the $\mu \mathrm{CT}$ signal was performed to separate Bio-Oss ${ }^{\circledR}$ granules from newly formed bone. A corresponding histological section of the $\mu \mathrm{CT}$ image was taken to judge for the separation of newly formed bone and Bio-Oss ${ }^{\circledR}$ granules (Figure $5 \mathrm{~A})$. Analysis of the $\mu \mathrm{CT}$ signal of the newly formed bone showed a significant $19 \%$ increase in BV/TV $(\mathrm{F} 0 ; 37[7] \%, \mathrm{~F} 125 ; 44[8] \%, \mathrm{P}=0.036)$ and a $9 \%$ increase in BMD (F0; 724 [93], F125; 792 [64], $\mathrm{P}=$ 0.036) of the F125 treated defects compared to the F0

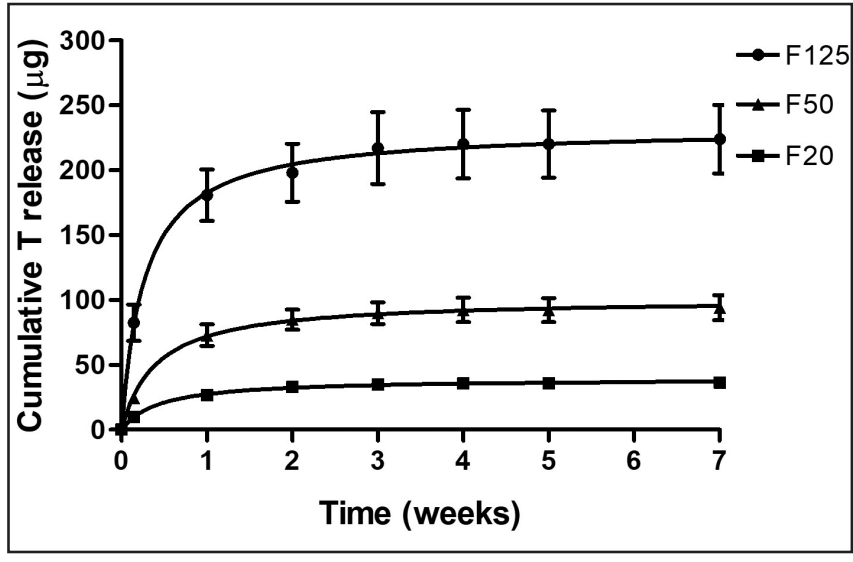

Figure 4. In vitro release of testosterone from testosterone coated collagen membranes. Cumulative in vitro release of testosterone from F20, F50 and F125 coated membranes $(n=3)$ over a period of 7 weeks.

treated defects after 6 weeks (Figure 5B, C), while no significant dose dependent increase in $\mathrm{BV} / \mathrm{TV}$ and BMD for F20 and F50 compared to F0 were observed at week 6 (Figure 5B, C). At week 12, no significant difference in BV/TV or BMD was observed for any of the treatments (Figure 5D, E).

\section{Histology}

Histological analysis at week 6

Light microscopical analysis of the 6 weeks specimens showed that the bone healing response in the various experimental groups was very similar. The bone defect as well as the Bio-Oss ${ }^{\circledR}$ granules could be easily discerned. The bone defects were found to be homogeneously filled with Bio-Oss ${ }^{\circledR}$ granules and granules were in close vicinity of the defect borders and bone was always bridging the small space between defect border and the Bio-Oss ${ }^{\mathbb{B}}$ granules (Figure 6A). Newly formed bone between the granules bridged the defect and sometimes callus formation at the buccal side was observed (Figure $6 \mathrm{~A})$. Bone was growing in between the Bio-Oss ${ }^{\mathbb{B}}$ granules and $\mathrm{Bio-Oss}^{\circledR}$ granules were covered for the major part with bone tissue. No indication for an inflammatory response were observed in any of the samples analysed (Figure 6B). The bone tissue was in close contact with the Bio-Oss ${ }^{\circledR}$ surface without an intervening non-mineralized tissue layer (Figure 6B). The bone that bridged the defect was not mature and had a lamellar appearance (Figure 6B). In some specimens, the Bio-Oss ${ }^{\circledR}$ granules were extending into the bone marrow cavity (Figure 6C) and ingrowth of new bone covered these granules (Figure 6D). Although a large quantity of bone was seen in the bone defects, defects were not completely closed with bone in some specimens. 


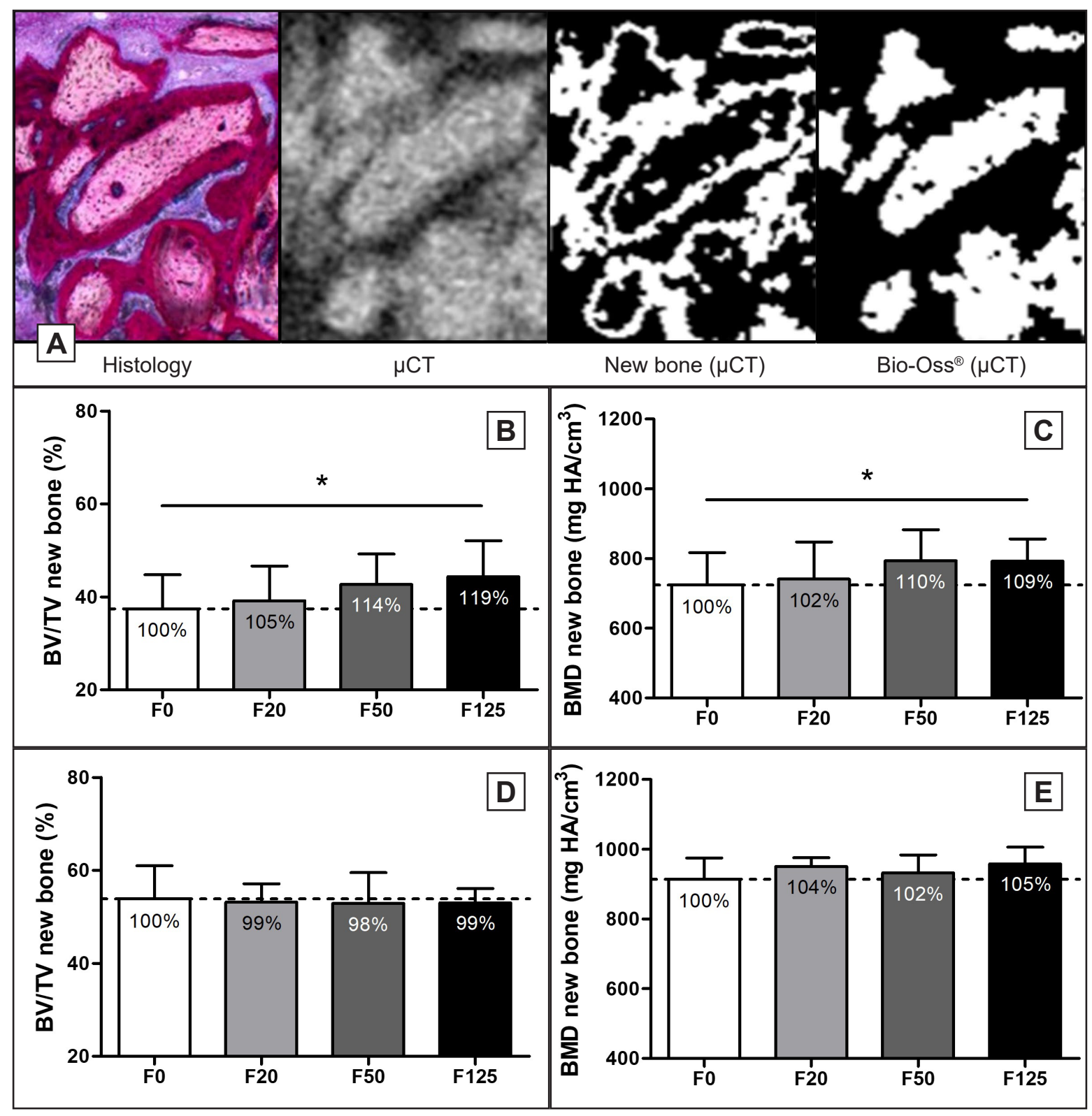

Figure 5. Micro-CT analysis of minipig bone defects.

$\mathrm{A}=$ By comparing histological sections to corresponding $\mu \mathrm{CT}$ images, thresholds were set to segment new bone from Bio-Oss ${ }^{\circledR}$ granules on $\mu \mathrm{CT}$.

$\mathrm{B}$ and $\mathrm{D}=$ Bone volume fraction $(\mathrm{BV} / \mathrm{TV})$ and $(\mathrm{C}, \mathrm{E})$ bone mineral density $(\mathrm{BMD})$ was determined for the new bone formed at $(\mathrm{B}, \mathrm{C})$ week 6 and (D, E) week 12.

Relative increases are shown as percentages within the bars.

In those specimens, a gap was present from the buccal side into the bone marrow cavity. This gap was always filled with non-mineralized tissue. Incomplete bone bridging was seen in three defects of the F0-group, in one defect of the F20-group, in one defect of the F50 and one defect of the F125-group. In a few sections, remnants of the membrane could be recognized. The remnants were surrounded by non-mineralized fibrous tissue without evident inflammatory response (Figure 6E). In the newly formed bone, voids were present, which were filled with bone marrow-like non-mineralized fibrous tissue, as characterized by the presence of fat tissue, blood vessels and a fibrous tissue matrix. The voids showed remodelling activity, as confirmed by the presence of osteoid and osteoblasts, which were lining the osteoid (Figure $6 \mathrm{~F})$. Occasionally, Bio-Oss ${ }^{\circledR}$ granules penetrated these remodelling voids. Such granules were found to be covered with osteoclast-like cells (Figure 6F). Still, no clear degradation of the Bio-Oss ${ }^{\circledR}$ granules was observed.

Histological analysis at week 12

Compared with 6 weeks of implantation, bone remodelling had proceeded, and the newly deposited 


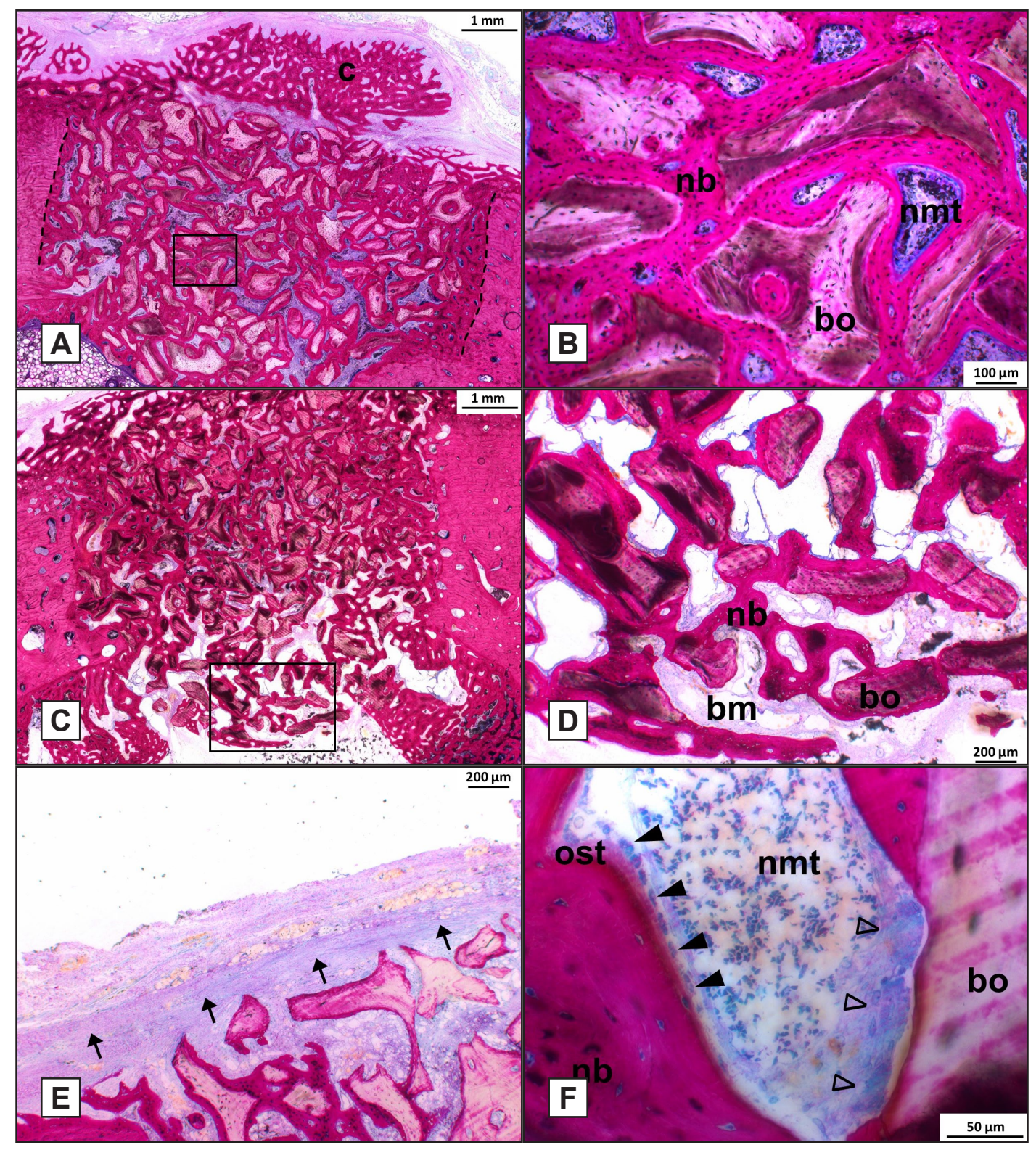

Figure 6. Histological analysis of bone defects at week 6 (Methylene Blue Basic fuchsin stain, original magnification x400). A $=$ Histological section of F125 treated defect.

$\mathrm{B}=$ High magnification of the boxed area in (A).

$\mathrm{C}=\mathrm{F} 125$ treated defect showing Bio-Oss ${ }^{\mathbb{R}}$ granules extending into the bone marrow.

$\mathrm{D}=$ High magnification of boxed area in (C).

$\mathrm{E}=\mathrm{F} 20$ treated defect showing remnants of the collagen membrane.

$\mathrm{F}=$ High magnification of F50 treated defect showing a void where osteoid tissue and osteoblasts lined the newly formed bone and osteoclast-like cells lined the surface of Bio-Oss ${ }^{\circledR}$ granules.

Dashed line $=$ defect border; dashed oval = osteon; $\mathrm{nb}=$ new bone; $\mathrm{cb}=$ cortical bone; $\mathrm{bo}=$ Bio-Oss ${ }^{\circledR} ; \mathrm{nmt}=$ non-mineralized tissue; closed arrowhead = osteoblasts; $\mathrm{bm}=$ bone marrow; ost = osteoid tissue; open arrowhead $=$ osteoclast-like cells.

bone had become more mature. Defect borders could be easily recognized, but significant remodelling of the defect borders had occurred (Figure 7A). The straight border, as created by the drilling process, had become irregular and osteons had formed close to the defect border (Figure 7B). In all defects, the Bio-Oss ${ }^{\circledR}$ granules could still be easily discerned. The granules were surrounded by the new bone (Figure 7C). Additionally, the membrane could no longer be recognized, and periosteal bone formation (callus) seemed reduced compared with the 6 weeks specimens. If the granules extended into the bone marrow cavity, then a large amount of bone was present around and between the granules (Figure 7D). Light microscopical analysis confirmed that there was also no indication for an inflammatory response were observed in any of the 12-weeks samples (Figure 7E). At higher magnification, osteoblasts with associated osteoid tissue could be observed at the interface of non-mineralized tissue and new bone (Figure 7F, G). 


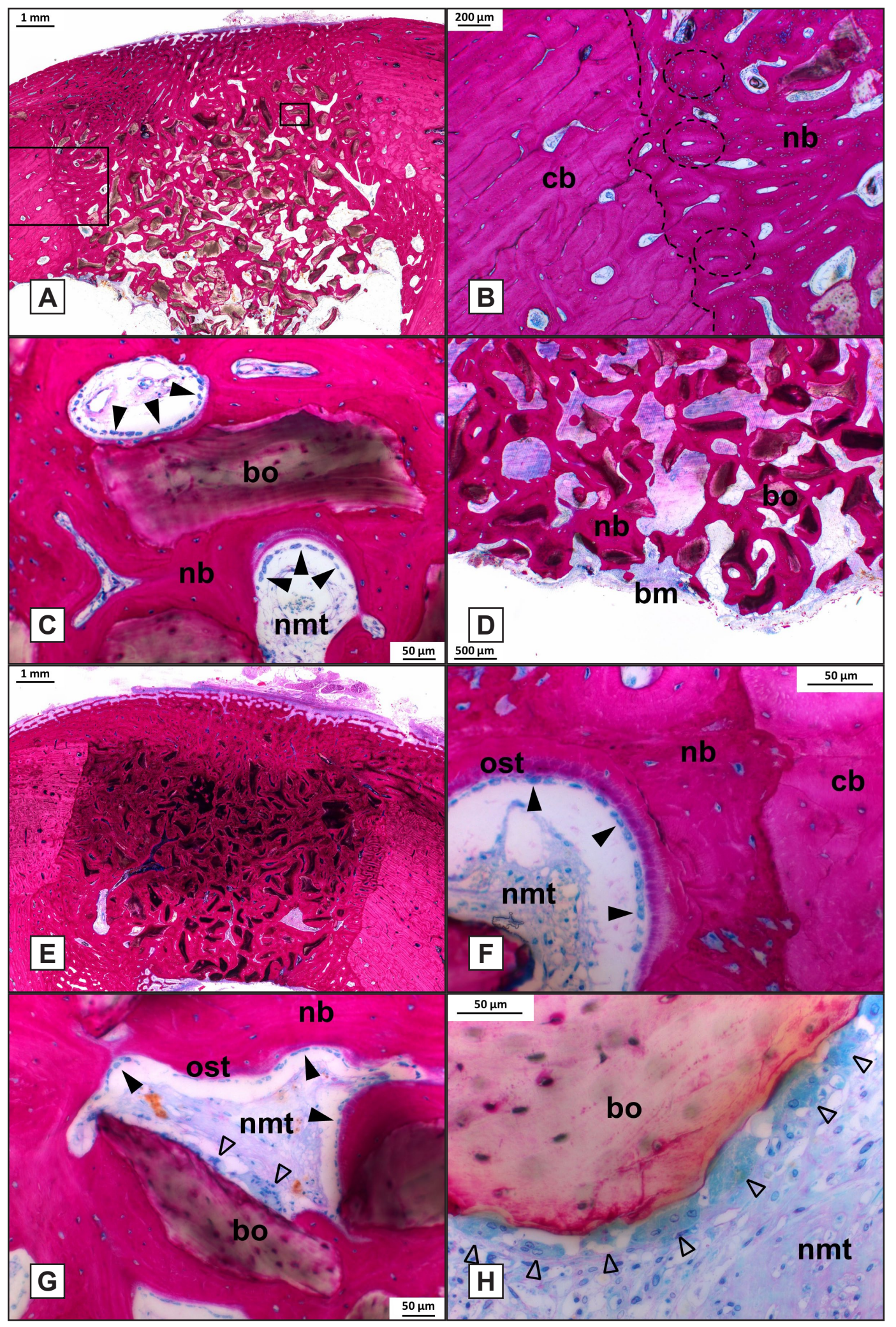

Figure 7. Histological analysis of bone defects at week 12 (Methylene Blue Basic fuchsin stain, original magnification x400). $\mathrm{A}=$ Histological section of F20 treated defect.

$\mathrm{B}=$ High magnification of the boxed area in (A), showing an irregular defect border.

$\mathrm{C}=$ High magnification of boxed area of $(\mathrm{A})$, showing Bio-Oss ${ }^{\circledR}$ granules completely surrounded by new bone.

$\mathrm{D}=\mathrm{F} 20$ treated defect where Bio-Oss ${ }^{\circledR}$ granules extending into the bone marrow cavity.

$\mathrm{E}=$ Histological section of a F50 treated defect showing the Bio-Oss ${ }^{\circledR}$ granules within the defect.

$\mathrm{F}$ and $\mathrm{G}=$ High magnification of a F20 treated defect showing a void where osteoid tissue and osteoblasts lined the newly formed bone.

$\mathrm{G}$ and $\mathrm{H}=$ Osteoclast-like cells lined the surface of Bio-Oss ${ }^{\circledR}$ granules.

Dashed line $=$ defect border; dashed oval $=$ osteon; $\mathrm{nb}=$ new bone; $\mathrm{cb}=$ cortical bone; bo $=$ Bio-Oss ${ }^{\circledR} ; \mathrm{nmt}=$ non-mineralized tissue; closed arrowhead $=$ osteoblasts; $\mathrm{bm}=$ bone marrow; ost = osteoid tissue; open arrowhead = osteoclast-like cells. 
Simultaneously, osteoclasts were observed on the Bio-Oss $^{\circledR}$ surface in locations were the Bio-Oss ${ }^{\circledR}$ granules were penetrating a void (Figure $7 \mathrm{G}, \mathrm{H}$ ). The presence of osteoid, osteoblasts and osteoclasts in the voids indicated that the bone remodelling process was still continuing and not inhibited by the released testosterone or alendronate.

Quantitative histological analysis of newly formed bone

A ROI of $6 \times 2 \mathrm{~mm}$ was positioned in the center and top of the defect and non-mineralized tissue, Bio-Oss ${ }^{\circledR}$ granules and new bone were manually selected, and area of the tissues was determined (Figure 2). Analysis of the percentage of area of the newly formed bone showed a significant $20 \%$ increase in area in the F125 coated membrane treated defects (40 [10]\%) compared to the F0 treated defects after 6 weeks $(33[10] \%, \mathrm{P}=$ 0.013 ) (Figure 8A). A dose dependent increase in area of new bone for F20 (F20; 35 [7]\%) and F50 (F50; $37[7] \%)$ compared to $\mathrm{F} 0$ was observed at week 6, but this was not significant (Figure 8A). At week 12, the total $\%$ of new bone was increased compared to week 6 (F0; 59 [7]\%, F20; $59[5] \%, \mathrm{~F} 50 ; 59[5] \%$ and F125; 58 [4]\%), but no increase in newly formed bone compared to F0 was observed (Figure 8B). No change in area of Bio-Oss ${ }^{\circledR}$ was observed in any of the treated groups at week 6 (F0; 33 [7]\%, F20; $33[6] \%$, F50; 303 $[8] \%$ and $\mathrm{F} 125 ; 34[8] \%)$ or week $12(\mathrm{~F} 0 ; 29[6] \%$, F20; $31[5] \%$, F50; $30[4] \%$ and F125; $33[6] \%)$.

A more detailed analysis of the 6-week dataset was performed to investigate individual responses to treatment. For this, the area of new bone in treated defects were compared to the area of new bone in the corresponding F0 treated defect of the same animal and values were normalized to F0 control $(100 \%)$. These data showed that in only 3 out of 8 F20 treated defects the area of new bone was increased compared to their corresponding F0 treated defects (Figure 9A). In the F50 treated defects 5 out of 8 defects showed an increase in new bone (Figure 9B), while in the F125 treated defects all defects showed an increase in new bone as compared to the F0 defect and an average $24 \%$ increase in new bone formation was observed when values were normalized to F0 controls $(100 \%)$ (Figure 9C).

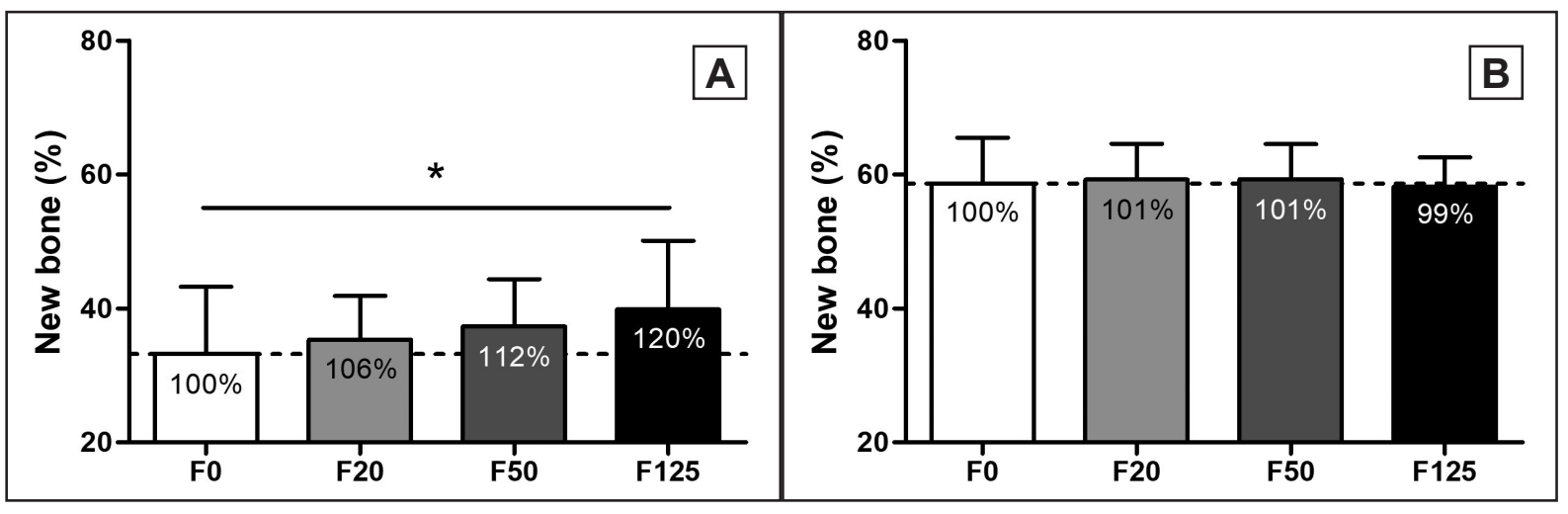

Figure 8. Histomorphometric analysis of new bone formation in minipig bone defects. The percentage of newly formed bone in the bone defects: $\mathrm{A}=$ at week $6 ; \mathrm{B}=$ at week 12 .

Relative increases are shown as percentages within the bars.

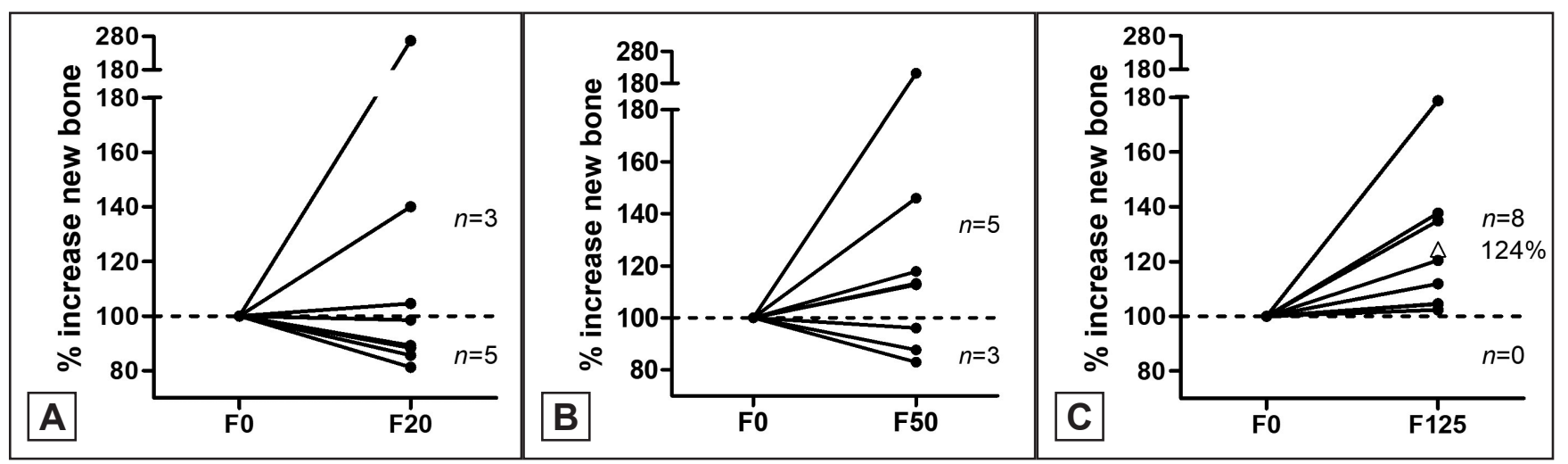

Figure 9. Increase in new bone relative to paired control defect. The relative increase in a treated defect is normalized to the new bone formation in the F0 defect (100\%) in the same animal. The number of animals that show an increase are depicted above the dashed line and the number of animals that show a reduced new bone formation are shown below the dashed line. The average relative increase in new bone in the F125 group is displayed by the open triangle. 


\section{DISCUSSION}

Implant placement after tooth extraction can be a challenge because of post-extraction bone resorption and dimensional changes of the alveolar ridge. GBR techniques, using bone substitute materials (i.e. bovine-derived xenografts and deproteinized bovine bone minerals) in combination with barrier membranes have been developed to promote bone formation. The goal of the present study was to evaluate the bone formation supportive properties of porcine derived resorbable collagen membranes coated with a PLGA solution containing both testosterone and alendronate in ancillary amounts and to test the applicability of coated membranes for GBR procedures. The in vitro assays with porcine and human derived bone specimens demonstrated that the combined use of dihydrotestosterone and alendronate had a synergistic and significant stimulating effect on bone formation and bone strength of the bone biopsies. The in vitro drug release study confirmed the continuous, sustained release of testosterone from the porcine membranes over a period of 3 4 weeks. Finally, the minipig study showed at 6 weeks a significant increase in bone formation in the mandibular defects that were covered with the membrane (F125) that was coated with $125 \mu \mathrm{g} /$ $\mathrm{cm}^{2}$ testosterone and $20 \mu \mathrm{g} / \mathrm{cm}^{2}$ alendronate. At 12 weeks, all bone defects were completely filled and no differences in bone formation were observed between the treatment groups.

Current bone regeneration strategies focus on the improvement of bone regeneration by drug delivery. The major aim is to change the balance in the bone remodelling cycle resulting in an enhanced bone formation. To achieve this, knowledge is required about the bone formation mechanism. Bone explant models are very appropriate to initially study the effect of pharmacological interventions on bone cell response. Using bone explant specimens, cellular diversity and spatial distribution of the various bone cells is maintained during several weeks of culturing and the explants are less costly and more standardized than animal models [23-25]. In addition, the bone explant culture model allows the use of healthy as well as diseased bone biopsies. These advantages of the bone explant culture model were evidently confirmed in the performed in vitro assays.

A challenge in the pharmacological improvement of bone regeneration is the optimal delivery of ancillary amounts of the drug(s). Efficiency of the therapeutic effect is achieved by maintaining a sustained and local drug release within the vicinity of the bone defect
[26]. This can be achieved by proper selection of the drug carrier. In view of this, PLGA is considered to be the polymer of choice for local delivery of small molecules to (bone) tissue for a prolonged treatment time. For example, PLGA coatings on tubular meshes have been applied successfully for the sustained release of antibiotics and an anti-restenosis drug $[27,28]$. This corroborates with our in vitro release data of PLGA-coated pericard membranes containing testosterone and justified the use of these membranes in the in vivo study.

For the in vivo study, the mandible of a minipig was chosen because of its size and osteogenic potential, which allowed the evaluation of different treatment options in one animal. The minipig model also shows close resemblance to human bone in terms of anatomical shape and dimensions, bone healing response as well as bone structure [29, 30]. It is possible to create properly sized defects for a standardized evaluation of different bone and tissue regeneration modalities. Therefore, the minipig is widely used as a 'proof-of principle' model [31-33].

The current clinical timeline for GBR using Bio-Oss ${ }^{\mathbb{B}}$ bone grafting material and membrane coverage is 6 months after which dental implants are installed [34]. The quality and quantity of the newly formed bone is assessed at the time of implant placement. Since the primary goal of the minipig study was to study if improved GBR could be achieved, we evaluated the healing of bone defects covered with degradable pericard membranes coated with various amounts of testosterone and a fixed amount of alendronate in ancillary amounts vs uncoated membranes at two time points ( 6 and 12 weeks). In the present study, no empty defects were created as control group, as the current standard approach in GBR involves always the placement of a bone grafting material. Histological analysis of the retrieved specimens indicated:

- All defects were uniformly filled with approximately $33 \%$ Bio-Oss $^{\circledR}$ with no significant changes between the various treatment groups or implantation times.

- Bone defect healing was uneventful with no signs of inflammation in any of the samples.

- Bio-Oss ${ }^{\circledR}$ granules were associated with the presence of osteoclasts, but degradation of the granules proceeded very slowly.

These observations do corroborate with other reports about the biological behaviour of Bio-Oss ${ }^{\circledR}$ granules [35-36]. Light microscopical images showed that 6 weeks after implantation still remnants of the pericard barrier membrane could be observed, whereas the membrane had degraded completely after 12 weeks. Evidently, membrane degradation proceeded 
faster in comparison to other studies. For example, Tovar et al. [37] used porcine pericardium collagen membranes for GBR of furcation defects in beagle dogs. The membrane gradually degraded from 6 to 12 weeks of implantation but was still not completely resorbed at 24 weeks. Also Hwang et al. [38], who compared commercially available collagen membranes from porcine skin with porcine pericardium membranes in a rabbit tibial defect model, observed that the skin derived membranes were almost completely degraded at 12 weeks, while the pericardium membranes remained. It has to be noticed that the degradation properties of collagen membranes are determined by the used processing technique for membrane fabrication. Processing steps, like sterilization technique and cross-linking, will affect the structural properties, which potentially can influence the degradation kinetics of a collagen membrane. Nevertheless, our histologic outcome confirmed that the membrane was maintained long enough to perform its barrier function.

Considering bone formation, the quantified data of the defects that contained only Bio-Oss ${ }^{\circledR}$ granules and were covered with a non-coated membrane showed that the percentage of bone ingrowth at 6 and 12 weeks of implantation is in agreement with other studies $[\underline{39}, \underline{40}]$. On the other hand, a dose dependent increase in new bone formation was observed at 6 weeks for the defects covered with membranes coated with alendronate and testosterone. Using F125 membranes, new bone formation significantly increased up to $24 \%$ compared to uncoated membranes. At 12 weeks, no significant difference in the percentage of bone ingrowth between the various groups was observed and all defects showed a filling percentage of almost 100\% (bone + BioOss $^{\circledR}$ granules). The sequentially increasing bone formation in the bone defects covered with drug treated membranes is undoubtedly attributable to the release of the alendronate and testosterone, which are known to have an improving effect on bone turnover and density [17]. The F125 membranes contained and released the highest amount of testosterone resulting in a significantly increased percentage of bone ingrowth. On basis of this finding, it can even be assumed that loading the membrane with a higher dose of testosterone will perhaps result in a further enhancement of bone formation. The lack of a difference in defect bone fill between the various experimental groups at week 12 is probably due to the fact that the defects were not critical-sized, which is characterized by spontaneous healing [41]. Considering the circular shape, relatively limited size and location of the created defect as well as the bone healing rate in minipigs, it can be supposed that this was the case. The reason that bone grafting is still applied in such defects is to stabilize the blood clot and to accelerate defect healing. Most likely, this was the case in the present study and natural defect closure occurred between 8 to 10 weeks of implantation. Therefore, at 12 weeks, there will be no further stimulating effect on bone formation for the drug releasing membranes.

In addition to the effect of the released alendronate and testosterone on the percentage of bone ingrowth at 6 weeks, the histological findings revealed that bone formation in the defects covered with the drug coated membranes appeared to occur from the cortical side of the bone defect. In view of this observation, an experimental study by Schwartz and co-workers [42] described the coverage of bone defects in the dog mandible by 6 different barrier membranes. Histological analyses demonstrated that angiogenesis and bone formation mainly arose from the bottom of the defect. Bone healing proceeds via different stages. During the repair stage, blood vessels start to penetrate into the deposited mineralized matrix and adequate blood supply favours the fast progression of the ossification process. Consequently, the increased bone formation as observed at the cortical side in the bone defects covered with coated membranes can be indicative that the testosterone and alendronate coating can be beneficial for bone formation at the top of the defect.

The maintenance and remodelling of bone is depending on the biomechanical loading condition. According to Wolff's Law, bone adapts to the loads under which it is placed. Lack of loading in terms of duration, magnitude and rate causes that bone undergoes adaptative changes of the bone structure, e.g. tooth extraction is associated with altered functional forces in the dimensions and profile of the alveolar ridge [43], The principles of Wolff's Law are also the rationale for the concept of immediate and early placement and loading of dental implants. Early loading can stimulate osteogenesis and can be used to influence the osseointegration of the implant as well as to prevent resorption of the alveolar ridge [44-46]. However, initial implant stability remains the major parameter for final implant success. This is the underlying rationale for bone regeneration procedures; grafting has to result in bone ingrowth into the defect to allow the stable installation of an oral implant. As mentioned before, the current waiting time between grafting and dental implant placement is 6 months and earlier implant installation will result in a reduced overall treatment time, which will benefit the patient. Considering the enhancing effect of the alendronate 
and testosterone containing membranes on GBR as measured by the presence of newly formed bone, these membranes represent a promising development for use in the bone regeneration indications or similar approaches. Nevertheless, their safety and efficacy will have to be proven in a human clinical follow-up study.

\section{CONCLUSIONS}

In conclusion, the data from this in vivo study indicate that F125 collagen membranes coated with testosterone and alendronate resulted in superior bone formation $(+24 \%)$ when values were normalized to control sites using uncoated collagen membranes. Normal bone remodelling and no signs of inflammation were observed indicating that coated membranes with alendronate and testosterone are a promising development to optimize the outcome and predictability of the bone regeneration approach. However, controlled clinical trials are needed to prove this.

\section{ACKNOWLEDGEMENTS AND DISCLOSURE STATEMENTS}

This work was partly supported by Osteo-Pharma B.V.; Oss, North Brabant, The Netherlands.

Jan A. Gossen is shareholder of Osteo-Pharma B.V.

Cindy J. J. M. van de Ven and Edwin J. W. Geven are employees of Osteo-Pharma B.V.

The authors would like to thank prof dr. Gert Meijer (Department of Dentistry, Radboud University Medical Center, Nijmegen, The Netherlands) for his support during the surgical procedures, prof dr. Peter van der Kraan (Department of Experimental Rheumatology, Radboud University Medical Center) for providing the human bone specimens, Nicole Bakker (Osteo-Pharma BV, Oss) for technical assistance with the in vitro studies on porcine and human bone explants, Natasja van Dijk and Martijn Martens (Department of Dentistry, Radboud University Medical Center) for preparing the histological PMMA sections and histological analyses.

\section{REFERENCES}

1. Araújo MG, Silva CO, Misawa M, Sukekava F. Alveolar socket healing: what can we learn? Periodontol 2000. 2015 Jun;68(1):122-34. [Medline: 25867983] [doi: 10.1111/prd.12082]

2. Kalsi AS, Kalsi JS, Bassi S. Alveolar ridge preservation: why, when and how. Br Dent J. 2019 Aug;227(4):264-274. [Medline: 31444438] [doi: 10.1038/s41415-019-0647-2]

3. Tawil G, Younan R. Clinical evaluation of short, machined-surface implants followed for 12 to 92 months. Int J Oral Maxillofac Implants. 2003 Nov-Dec;18(6):894-901. [Medline: 14696666] [doi: 10.1016/j.prosdent.2004.04.008]

4. Avila-Ortiz G, Gubler M, Romero-Bustillos M, Nicholas CL, Zimmerman MB, Barwacz CA. Efficacy of Alveolar Ridge Preservation: A Randomized Controlled Trial. J Dent Res. 2020 Apr;99(4):402-409. [Medline: 32050833] [doi: 10.1177/0022034520905660]

5. Avila-Ortiz G, Chambrone L, Vignoletti F. Effect of alveolar ridge preservation interventions following tooth extraction: A systematic review and meta-analysis. J Clin Periodontol. 2019 Jun;46 Suppl 21:195-223. [Medline: 30623987] [doi: $10.1111 /$ jepe.13057]

6. Canellas JVDS, Ritto FG, Figueredo CMDS, Fischer RG, de Oliveira GP, Thole AA, Medeiros PJD. Histomorphometric evaluation of different grafting materials used for alveolar ridge preservation: a systematic review and network metaanalysis. Int J Oral Maxillofac Surg. 2020 Jun;49(6):797-810. [Medline: 31699633] [doi: 10.1016/j.ijom.2019.10.007]

7. Faria-Almeida R, Astramskaite-Januseviciene I, Puisys A, Correia F. Extraction Socket Preservation with or without Membranes, Soft Tissue Influence on Post Extraction Alveolar Ridge Preservation: a Systematic Review. J Oral Maxillofac Res. 2019 Sep 5;10(3):e5. [Medline: 31620267] [PMC free article: 6788420] [doi: 10.5037/jomr.2019.10305]

8. Tonetti MS, Jung RE, Avila-Ortiz G, Blanco J, Cosyn J, Fickl S, Figuero E, Goldstein M, Graziani F, Madianos P, Molina A, Nart J, Salvi GE, Sanz-Martin I, Thoma D, Van Assche N, Vignoletti F. Management of the extraction socket and timing of implant placement: Consensus report and clinical recommendations of group 3 of the XV European Workshop in Periodontology. J Clin Periodontol. 2019 Jun;46 Suppl 21:183-194. [Medline: 31215112] [doi: 10.1111/jepe.13131]

9. Galindo-Moreno P, Suárez López Del Amo F, Faria-Almeida R, Almeida BL, Astramskaite-Januseviciene I, Barootchi S, Borges T, Correia A, Correia F, Majzoub J, Padial-Molina M, Pranskunas M, Puisys A, Ramanauskaite A, Ravida A, Starch-Jensen T, Tattan M. The $2^{\text {nd }}$ Baltic Osseointegration Academy and Lithuanian University of Health Sciences Consensus Conference 2019. Summary and Consensus Statements: Group II - Extraction Socket Preservation Methods and Dental Implant Placement Outcomes within Grafted Sockets. J Oral Maxillofac Res. 2019 Sep 5;10(3):e9. [Medline: 31620271] [PMC free article: 6788424] [doi: 10.5037/jomr.2019.10309]

10. Hosny MS, Radi IA. Evidence Is Unclear About the Best Material and Technique Required for Alveolar Ridge Preservation for Dental IMPLANT SITE Development. J Evid Based Dent Pract. 2019 Sep;19(3):295-297. [Medline: 31732105] [doi: 10.1016/j.jebdp.2019.101338] 
11. Li F, Yu F, Liao X, Wu C, Wang Y, Li C, Lou F, Li B, Yin B, Wang C, Ye L. Efficacy of Recombinant Human BMP2 and PDGF-BB in Orofacial Bone Regeneration: A Systematic Review and Meta-analysis. Sci Rep. 2019 May 30;9(1):8073. [Medline: 31147568] [PMC free article: 6542831] [doi: 10.1038/s41598-019-44368-z]

12. Moreno Sancho F, Leira Y, Orlandi M, Buti J, Giannobile WV, D’Aiuto F. Cell-Based Therapies for Alveolar Bone and Periodontal Regeneration: Concise Review. Stem Cells Transl Med. 2019 Dec;8(12):1286-1295. [Medline: 31692298] [PMC free article: 6877771] [doi: 10.1002/sctm.19-0183]

13. Liu Y, Sun X, Yu J, Wang J, Zhai P, Chen S, Liu M, Zhou Y. Platelet-Rich Fibrin as a Bone Graft Material in Oral and Maxillofacial Bone Regeneration: Classification and Summary for Better Application. Biomed Res Int. 2019 Dec 6;2019:3295756. [Medline: 31886202] [PMC free article: 6925910] [doi: 10.1155/2019/3295756]

14. Shaheen MY, Basudan AM, de Vries RB, van den Beucken JJJP, Jansen JA, Alghamdi HS. Bone Regeneration Using Antiosteoporotic Drugs in Adjunction with Bone Grafting: A Meta-Analysis. Tissue Eng Part B Rev. 2019 Dec;25(6):500509. [Medline: 31411119] [doi: 10.1089/ten.teb.2019.0132]

15. Frisoli A Jr, Chaves PH, Pinheiro MM, Szejnfeld VL. The effect of nandrolone decanoate on bone mineral density, muscle mass, and hemoglobin levels in elderly women with osteoporosis: a double-blind, randomized, placebo-controlled clinical trial. J Gerontol A Biol Sci Med Sci. 2005 May;60(5):648-53. [Medline: 15972619] [doi: 10.1093/gerona/60.5.648]

16. Anastasilakis AD, Polyzos SA, Yavropoulou MP, Makras P. Combination and sequential treatment in women with postmenopausal osteoporosis. Expert Opin Pharmacother. 2020 Mar;21(4):477-490. [Medline: 31990595] [doi: $10.1080 / 14656566.2020 .1717468$ ]

17. Sim IeW, Ebeling PR. Treatment of osteoporosis in men with bisphosphonates: rationale and latest evidence. Ther Adv Musculoskelet Dis. 2013 Oct;5(5):259-67. [Medline: 24101947] [PMC free article: 3791089] [doi: $10.1177 / 1759720 \mathrm{X} 13500861]$

18. Doi Y, Miyazaki M, Yoshiiwa T, Hara K, Kataoka M, Tsumura H. Manipulation of the anabolic and catabolic responses with BMP-2 and zoledronic acid in a rat femoral fracture model. Bone. 2011 Oct;49(4):777-82. [Medline: 21777711] [doi: 10.1016/j.bone.2011.07.005]

19. Mohamad NV, Soelaiman IN, Chin KY. A concise review of testosterone and bone health. Clin Interv Aging. 2016 Sep 22;11:1317-1324. [Medline: 27703340] [PMC free article: 5036835] [doi: 10.2147/CIA.S115472]

20. Kasperk CH, Wergedal JE, Farley JR, Linkhart TA, Turner RT, Baylink DJ. Androgens directly stimulate proliferation of bone cells in vitro. Endocrinology. 1989 Mar;124(3):1576-8. [Medline: 2521824] [doi: 10.1210/endo-124-3-1576]

21. Cheng BH, Chu TM, Chang C, Kang HY, Huang KE. Testosterone delivered with a scaffold is as effective as bone morphologic protein-2 in promoting the repair of critical-size segmental defect of femoral bone in mice. PLoS One. 2013 Aug 5;8(8):e70234. [Medline: 23940550] [PMC free article: 3733987] [doi: 10.1371/journal.pone.0070234]

22. Gossen JA. Compositions and products for use in the treatment of bone fractures and defects. Eur. Pat. Appl. EP3164133. 3 May 2017. [URL: https://patents.google.com/patent/EP3164133A1/en]

23. Marino S, Staines KA, Brown G, Howard-Jones RA, Adamczyk M. Models of ex vivo explant cultures: applications in bone research. Bonekey Rep. 2016 Jun 29;5:818. [Medline: 27408711] [PMC free article: 4926536] [doi: 10.1038/bonekey.2016.49]

24. Bellido T, Delgado-Calle J. Ex Vivo Organ Cultures as Models to Study Bone Biology. JBMR Plus. 2020 Feb 14;4(3):10.1002/jbm4.10345. [Medline: 32161838] [PMC free article: 7059827] [doi: 10.1002/jbm4.10345]

25. de Vries-van Melle ML, Mandl EW, Kops N, Koevoet WJ, Verhaar JA, van Osch GJ. An osteochondral culture model to study mechanisms involved in articular cartilage repair. Tissue Eng Part C Methods. 2012 Jan;18(1):45-53. [Medline: 21875392] [PMC free article: 3245721] [doi: 10.1089/ten.tec.2011.0339]

26. Nadar RA, van den Beucken JJP, Leeuwenburgh SCG. Chapter 10 - Pharmalogical interventions targeting bone diseases in adjunction wiht bone grafting. In: Dental Implants and Bone Grafts. Materials and Biological Issues. United Kingdom: Elsevier Ltd; 2020 Jan. p. 251-80. [doi: 10.1016/B978-0-08-102478-2.00011-8]

27. Elsner JJ, Zilberman M. Antibiotic-eluting bioresorbable composite fibers for wound healing applications: microstructure, drug delivery and mechanical properties. Acta Biomater. 2009 Oct;5(8):2872-83. [Medline: 19416766] [doi: 10.1016/j.actbio.2009.04.007]

28. Mylonaki I, Trosi O, Allémann E, Durand M, Jordan O, Delie F. Design and characterization of a perivascular PLGA coated PET mesh sustaining the release of atorvastatin for the prevention of intimal hyperplasia. Int $\mathrm{J}$ Pharm. 2018 Feb 15;537(1-2):40-47. [Medline: 29246440] [doi: 10.1016/j.ijpharm.2017.12.026]

29. Hönig JF, Merten H. [Das Göttinger Miniatureschwein (GMS) als Versuchstier in der humanmedizinischen osteologischen Grundlagenforschung]. Z Zahnärztl Implantol 1993;2:244-54.

30. Cui Y, Lu C, Chen B, Han J, Zhao Y, Xiao Z, Han S, Pan J, Dai J. Restoration of mandibular bone defects with demineralized bone matrix combined with three-dimensional cultured bone marrow-derived mesenchymal stem cells in minipig models. J Mater Sci Mater Med. 2018 Aug 31;29(9):147. [Medline: $\underline{30171486}$ ] [doi: 10.1007/s10856-018-6152-3]

31. Donos N, Dereka X, Mardas N. Experimental models for guided bone regeneration in healthy and medically compromised conditions. Periodontol 2000. 2015 Jun;68(1):99-121. [Medline: 25867982] [doi: 10.1111/prd.12077]

32. Buser D, Hoffmann B, Bernard JP, Lussi A, Mettler D, Schenk RK. Evaluation of filling materials in membrane--protected bone defects. A comparative histomorphometric study in the mandible of miniature pigs. Clin Oral Implants Res. 1998 Jun;9(3):137-50. [Medline: 10530128] [doi: 10.1034/j.1600-0501.1998.090301.x] 
33. Jensen SS, Yeo A, Dard M, Hunziker E, Schenk R, Buser D. Evaluation of a novel biphasic calcium phosphate in standardized bone defects: a histologic and histomorphometric study in the mandibles of minipigs. Clin Oral Implants Res. 2007 Dec;18(6):752-60. [Medline: 17888014] [doi: 10.1111/j.1600-0501.2007.01417.x]

34. Serrano CA, Castellanos P, Botticelli D. Use of Combination of Allografts and Xenografts for Alveolar Ridge Preservation Procedures: A Clinical and Histological Case Series. Implant Dent. 2018 Aug;27(4):467-473. [Medline: 30028391] [doi: 10.1097/ID.0000000000000792]

35. Caneva M, Botticelli D, Pantani F, Baffone GM, Rangel IG Jr, Lang NP. Deproteinized bovine bone mineral in marginal defects at implants installed immediately into extraction sockets: an experimental study in dogs. Clin Oral Implants Res. 2012 Jan;23(1):106-12. [Medline: 21545532] [doi: 10.1111/j.1600-0501.2011.02202.x]

36. van Houdt CIA, Ulrich DJO, Jansen JA, van den Beucken JJJP. The performance of CPC/PLGA and Bio-Oss ${ }^{\circledR}$ for bone regeneration in healthy and osteoporotic rats. J Biomed Mater Res B Appl Biomater. 2018 Jan;106(1):131-142. [Medline: 27889939] [doi: 10.1002/jbm.b.33801]

37. Tovar N, Witek L, Neiva R, Marão HF, Gil LF, Atria P, Jimbo R, Caceres EA, Coelho PG. In vivo evaluation of resorbable supercritical $\mathrm{CO}_{2}$-treated collagen membranes for class III furcation-guided tissue regeneration. J Biomed Mater Res B Appl Biomater. 2019 Jul;107(5):1320-1328. [Medline: 30199603] [doi: 10.1002/jbm.b.34225]

38. Hwang JW, Kim S, Kim SW, Lee JH. Effect of Extracellular Matrix Membrane on Bone Formation in a Rabbit Tibial Defect Model. Biomed Res Int. 2016;2016:6715295. [Medline: 27047963] [PMC free article: 4800078] [doi: 10.1155/2016/6715295]

39. Tovar N, Jimbo R, Gangolli R, Perez L, Manne L, Yoo D, Lorenzoni F, Witek L, Coelho PG. Evaluation of bone response to various anorganic bovine bone xenografts: an experimental calvaria defect study. Int J Oral Maxillofac Surg. 2014 Feb;43(2):251-60. [Medline: 23948358] [doi: 10.1016/j.ijom.2013.07.005]

40. Mardinger O, Vered M, Chaushu G, Nissan J. Histomorphometrical analysis following augmentation of infected extraction sites exhibiting severe bone loss and primarily closed by intrasocket reactive soft tissue. Clin Implant Dent Relat Res. 2012 Jun;14(3):359-65. [Medline: 20491820] [doi: 10.1111/j.1708-8208.2010.00281.x]

41. Schemitsch EH. Size Matters: Defining Critical in Bone Defect Size! J Orthop Trauma. 2017 Oct;31 Suppl 5:S20-S22. [Medline: 28938386] [doi: 10.1097/BOT.0000000000000978]

42. Schwarz F, Rothamel D, Herten M, Wüstefeld M, Sager M, Ferrari D, Becker J. Immunohistochemical characterization of guided bone regeneration at a dehiscence-type defect using different barrier membranes: an experimental study in dogs. Clin Oral Implants Res. 2008 Apr;19(4):402-15. [Medline: 18324961] [doi: 10.1111/j.1600-0501.2007.01486.x]

43. Frost HM. Wolff's Law and bone's structural adaptations to mechanical usage: an overview for clinicians. Angle Orthod. 1994;64(3):175-88. [Medline: 8060014$]$

44. Bousdras VA, Walboomers F, Jansen JA, Cunningham JL, Blunn G, Petrie A, Jaecques S, Naert IE, Sindet-Pedersen S, Goodship AE. Immediate functional loading of single-tooth TiO2 grit-blasted implant restoration. A controlled prospective study in a porcine model. Part II: Histology and histomorphometry. Clin Implant Dent Relat Res. 2007 Dec;9(4):207-16. [Medline: 18031442] [doi: 10.1111/j.1708-8208.2007.00039.x]

45. Leucht P, Kim JB, Wazen R, Currey JA, Nanci A, Brunski JB, Helms JA. Effect of mechanical stimuli on skeletal regeneration around implants. Bone. 2007 Apr;40(4):919-30. [Medline: 17175211] [PMC free article: 1987325] [doi: 10.1016/j.bone.2006.10.027]

46. Wazen RM, Currey JA, Guo H, Brunski JB, Helms JA, Nanci A. Micromotion-induced strain fields influence early stages of repair at bone-implant interfaces. Acta Biomater. 2013 May;9(5):6663-74. [Medline: 23337705] [PMC free article: $\underline{3622828}$ ] [doi: 10.1016/j.actbio.2013.01.014]

\author{
To cite this article: \\ van Oirschot BA, Jansen JA, van de Ven CJ, Geven EJW, Gossen JA. \\ Evaluation of Collagen Membranes Coated with Testosterone and Alendronate to Improve Guided Bone Regeneration \\ in Mandibular Bone Defects in Minipigs \\ J Oral Maxillofac Res 2020;11(3):e4 \\ URL: http://www.ejomr.org/JOMR/archives/2020/3/e4/v11n3e4.pdf \\ doi: $10.5037 /$ jomr.2020.11304
}

Copyright (C) van Oirschot BA, Jansen JA, van de Ven CJ, Geven EJW, Gossen JA. Published in the JOURNAL OF ORAL \& MAXILLOFACIAL RESEARCH (http://www.ejomr.org), 30 September 2020.

This is an open-access article, first published in the JOURNAL OF ORAL \& MAXILLOFACIAL RESEARCH, distributed under the terms of the Creative Commons Attribution-Noncommercial-No Derivative Works 3.0 Unported License, which permits unrestricted non-commercial use, distribution, and reproduction in any medium, provided the original work and is properly cited. The copyright, license information and link to the original publication on (http://www.ejomr.org) must be included. 